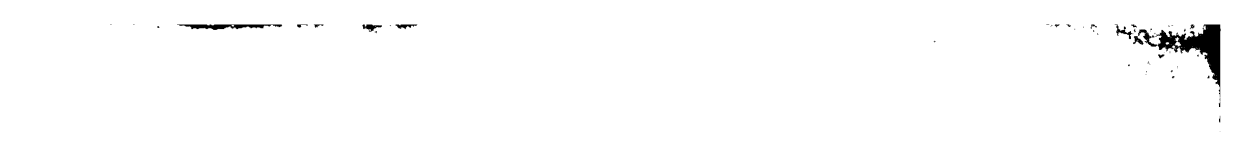

\title{
THE VALUE OF OUT-PATIENT WORK AMONG THE INSANE.*
}

BY A. WARREN STEARNS, M.D.,

Assistant Professor of Neurology Tufts Medical School and Assistant Physician Psychopathic Hospital, Out-Patient Department, Boston, Mass.

One of the most important developments in the caring for patients with nervous and mental diseases has been the extension of out-patient work by state hospitals. This work is new enough so that it seems worth while for those engaged in it to compare notes frequently. This paper aims to describe and to discuss briefly the work of the Out-Patient Department in the Boston Psychopathic Hospital, this department now being in its fifth year, and so one of the oldest.

The clinic is held daily from 2 to 4 p. m., and Wednesday evenings.

There are three departments, namely:

I. Medical.

2. Social.

3. Psychological.

The medical department is made up of a part-time or visiting staff, who do only out-patient work, assisted by internes assigned from the house staff.

The social-service and psychological departments do both house and out-patient work and are not exclusively attached to the outpatient department.

Upon coming to the hospital, the patient is met by a clinic manager, who takes the history, and directs the patient to the different departments. Much time is saved by supplying social agencies with a blank history form so that most of their patients come with a complete typewritten history. These patients can then be referred directly for physical examination, and if the problem is one of defect, to the psychologist, reaching the doctor when completely examined. If the problem is not one of defect or is doubtful, the

* Being contributions of the Massachusetts Commission on Mental Diseases, Series of 1918. Read at the seventy-third annual meeting of the American Medico-Psychological Association, New York, May 29-June I, I9I7.

42 
patient is referred to the doctor after the history has been taken and all physical examination made. AWassermann blood test is made on every patient. As the clinical manager is attached to the social-service department, she has in mind the social needs of each case, and can call the attention of the social-service department to such need, but most patients are referred to the social-service department by the doctor after his interview. If diagnosis is impossible and more observation necessary, or if the patient has a psychosis, he is now referred for admission to the house.

During the last hospital year, October I, 19I5, to October I, 1916, I 485 new patients were received at the department, and 926I total visits were made.

The sources from which these new patients came were as follows :

Psychopathic hospital (after care)............4 413

Charitable organizations $\ldots \ldots \ldots \ldots \ldots \ldots \ldots \ldots, 402$

Other hospitals $\ldots \ldots \ldots \ldots \ldots \ldots \ldots \ldots \ldots \ldots$. 93

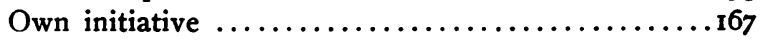

Doctors $\ldots \ldots \ldots \ldots \ldots \ldots \ldots \ldots \ldots \ldots \ldots$. 104

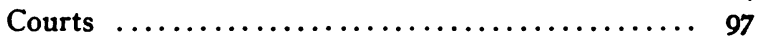

Schools $\ldots \ldots \ldots \ldots \ldots \ldots \ldots \ldots \ldots \ldots \ldots \ldots \ldots, \quad 69$

Miscellaneous $\ldots \ldots \ldots \ldots \ldots \ldots \ldots \ldots \ldots \ldots, \quad 40$

The following diagnoses were made:

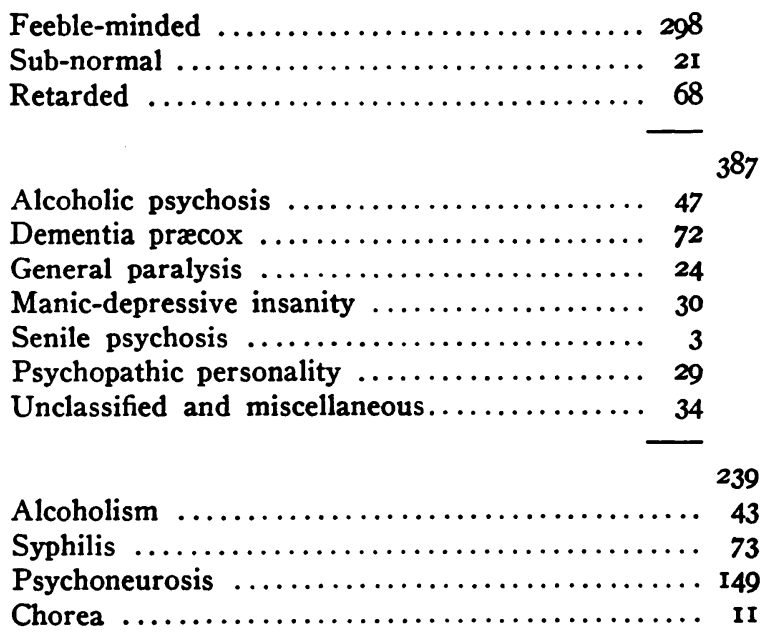




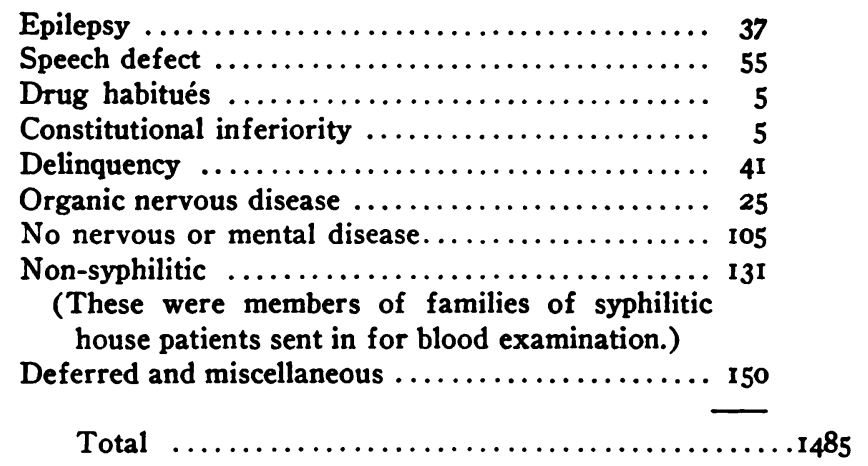

About one-half of the patients are problem children, the figures of January, 1917, illustrating this:

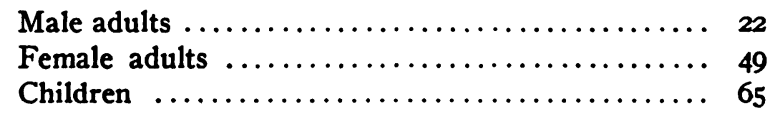

Although to quite a large extent this is a consultation clinic, and diagnosis is the essential object sought, the following different forms of treatment are used:

Hydrotherapy.-The hospital is equipped with a standard hydrotherapeutic room, to which out-patients are referred, usually being given three treatments a week.

Psychotherapy.-Patients requiring psychotherapeutic treatment are referred to special workers along this line.

Social-Service.-Some patients are referred for more investigation to aid diagnosis, others for employment, a special worker being maintained who has charge of the latter. Many are referred for supervision, it being found that certain tractable insane persons, or those with abnormal personalities, can get along satisfactorily in the community with a varying degree of social-service supervision.

Speech Training.-A special clinic for speech defects is in operation for this class of cases, being held two afternoons a week.

Men's Club.-An informal club, with weekly meetings, has been organized principally to interest and help alcoholic patients, but other types are admitted. The active membership is now 86 men. A women's auxiliary, composed of wives of members, has also 
been organized. This club seeks to furnish a certain amount of entertainment and recreation to keep the patients' association with the hospital, and to encourage members to help each other.

Anti-Syphilitic Treatment.-All patients with a positive Wassermann or evidence of syphilis are referred to special workers who have charge of the syphilis problem.

House Observation.-As stated above, patients needing observation or temporary care are referred directly to the house.

An important aid to efficient work is the follow-up system. At each visit of a patient a slip is sent to a special follow-up worker, giving date of next visit desired. If the patient does not report on that date a formal printed letter is sent as a reminder. If this does not bring the patient the telephone is tried, and if unsuccessful, the patient is visited by this worker.

Of 577 new patients told to return, 312 came without, 48 with, a reminder.

Of 375 house cases referred to the out-patient department, I84 came without, 38 with, a reminder.

Of 6635 total vists, 5852 came without, 783 with, a reminder.

The exact expense of the out-patient department cannot be given at this time, but appears to be between $\$ 1.50$ and $\$ 2.00$ a visit. This should be compared with the 18 cents to 57 cents per visit, as given by Mr. Davis in a report of a committee on outpatient service of the American Hospital Association.

For some time the writer has been of the opinion that a great many of the patients admitted to the house for Io days' observation could be as well handled by the out-patient department, and with this in mind 100 consecutive house admissions were examined and the opinion formed that 35 of these cases could have been cared for as well by the out-patient department without house admission. These are largely cases where diagnosis is the object sought. Obviously an out-patient visit would be much less expensive than Io days' house observation. From the experience of the past five years, a few points seem of special importance:

I. Inasmuch as the clinic is quite largely for consultation, there must be a well-trained and mature psychiatrist in charge. The large proportion of neurological material commonly forming an out-patient department makes some special training in this branch necessary. 
2. Lack of adequate facilities for caring for psychoneurotics is apparent, it being almost impossible to get free beds for this class of patients.

3. Need of elaborate equipment and many workers to carry on psychiatric out-patient work.

The examination is so complex that unless several persons can be engaged at once, few patients can be examined in an afternoon. This makes it seem wiser to hold out-patient clinics at hospitals where entire staff will be available, rather than in outlying districts. Prejudice of people against going to hospitals does not seem to be a sufficient argument to warrant the waste of effort entailed by sending a staff of a hospital to distant points.

4. The important position of social-service in out-patient work.

Doctors must realize this and give the social worker more recognition, just as a trained nurse or psychologist goes into certain detail better than a doctor, so a trained social worker is fitted to take charge of that branch of our work under medical supervision.

5. Out-patient departments are an advantage: First, to patients, in that many prefer staying at home and are happier and better off there, as are their families; second, to the state, in that home care can save much expense under supervision. With stimulated and instructed family interests, many now a burden to the state may be self-supporting ; third, to the doctors themselves, as they see a vast variety of nervous and mental disease not seen at the hospitals and so get a broader training. It also furnishes a place where psychiatry can be kept pure, as doctors and special workers connected with social agencies and courts get a one-sided experience and do not become good psychiatrists. By working parttime in out-patient clinics connected with hospitals, they can keep in touch with the whole field.

\section{DISCUSSION}

Dr. Briggs.-Mr. President, I should like to say that the out-patient departments as organized in Massachusetts and now in New York, constitute the first organized effort for the prevention of insanity in this country. Out-patient departments have been used in Massachusetts in two hospitals for many years. When the State Board of Insanity asked the State Hospitals of Massachusetts, one and all to establish them, the response was immediate and successful, and to Dr. Stearns should be given the credit of this success in large measure. He visited each hospital, he 
helped in the organization, in the forms used in the different records and in many ways the assistance given by him was responsible for this success of the movement. It was predicted that it was more or less of a fad and that it would soon die out, but instead of that it has grown steadily to very large proportions; and I think that every superintendent who has an outpatient department has felt that he is doing good work in the prevention of insanity. Physicians in the country towns where the clinics are held bring patients for consultation, or attend the clinics and ask the superintendents who have had much experience in the care of the insane, advice concerning their cases. The early patients attend the clinics and the discharged patients report there, obviating the necessity of return to the hospital; and, therefore, I feel that every state should organize outpatient departments as a preventive measure.

Dr. Ostrander.-Mr. President, I would like to state that New York and Massachusetts are not the only states that are doing work of this kind. There is an out-patient clinic in connection with the Psychopathic Hospital at Ann Arbor, and the Kalamazoo Hospital, of which I have charge, have four out-patient departments, and these are conducted with out any help whatever from the state of Michigan. There is no state provision for financing any such thing. We have gone to county officers and asked permission to start these clinics in their midst and they have paid the expense, and I am not sure but that is the best way. The plan is no longer experimental, we no longer have to ask the counties to let us come to them and establish these clinics. They are sending word to us asking us to come to them. The idea is popular out our way, and I believe it is doing a great deal of good. I hope Dr. Briggs will hereafter add Michigan to the states he has already named as doing work in this line.

DR. BRIGGs.-Mr. President, I referred to out-patient departments as a state policy and my remarks should be regarded as applying to that proposition only.

The President.-This work is actively progressing in the state of New York. Every hospital of this state caring for the insane has its out-patient department, and considerable embarrassment has arisen from the fact that our clinics are simply overwhelmed by the numbers of patients calling for advice in regard to treatment.

During the past month in our city of Binghamton, every Monday afternoon our clinic has cared for many patients and the members of the hospital staff who have undertaken to carry it on have found it a serious task. We feel that unless the state comes to our rescue and gives us more money and more help we shall not be able to carry the clinics anywhere nearly as far as they should be carried in our part of the state. I think Dr. Pilgrim might give us some information on this subject as Chairman of the New York State Hospital Commission. 
Dr. Pilarim.-Mr. President, I can only say that every hospital has from one to four clinics of this kind. At Poughkeepsie they have one in the city itself, another at Peekskill, one at Mt. Vernon, and we are about to start another in Yonkers. As Dr. Wagner says, the great trouble is that owing to vacancies on our medical staffs we are unable to meet the demands which have been urgently placed before us. We could, if we had a sufficient number of physicians, conduct, with success, a clinic or an out-patient department in every city of the state; but we are now so short of medical men as to make this impossible.

DR. Briggs.-Mr. President, I would like to ask Dr. Houston to say a word about starting these clinics; how after starting one or two he had applications to start others.

Dr. Houston.-Mr. President, the Northampton State Hospital holds clinics, one each week, in three cities besides at the institution itself. Many cases are seen at these clinics that would never come to the hospital, and our sphere is thus widely extended. Furthermore, the public has shown its realization of our intent and efforts, and thus the hospital has been placed on a better footing with the public. This was discussed so thoroughly at out meetings a year ago that it hardly seems advisable now to repeat what was said at that time.

I beg to say that I cannot agree with Dr. Stearns that the study of medicine or practice of medicine unfits a person for the position of social worker. It may be true, as Dr. Stearns' experience, has shown, that non-medical persons may have a special adaptability for such work, but if such adaptability is also possessed by a medical person, such individual is correspondingly better fitted for the position of social worker in a state hospital. The social worker mentioned by Dr. Stearns seems to be able to make "snap diagnoses" of mental cases. She would be better able to make diagnoses if she were a physician with several years of experience.

The Northampton State Hospital was one of the first in the country to employ a woman physician for this work, the date being October, I9II. Undoubtedly there have been others who began earlier, but this was one of the earliest, and I have yet to find a social service worker more capable than the officer mentioned, not because she is a medical woman necessarily, but because there is combined in one individual an adaptibility to do social service work with the qualifications and experience of a medical officer.

Dr. Strarns.-Mr. President, just a word about the expense. I believe the average cost of out-patient work varies from 18 cents to 57 cents per visit. Our work has cost more than that; it has averaged $\$ 1.50$ per visit. Of 9200 visits some of which were not more than five minutes in length, the average cost to the state was $\$ 1.50$; so that there is something to be said along the lines of economizing and yet this appears to be greater economy than State Hospital care. 
As to the social service work, I believe physicians make very good social service workers, and medical training is an excellent background. I have no difference with Dr. Houston in this regard. I merely wanted to say that it was perhaps too much to ask a person to go through a medical school in preparation for social work; that physicians doing all sorts of work could not do better in this line than others, and I think social service work can be done by a less highly trained and less expensive person. 